\title{
Ensino Remoto Emergencial de música no contexto da pandemia de Covid-19: significações de professores
}

\section{Emergency Remote Teaching of music in the context of the Covid-19 pandemic: significations of teachers}

\author{
Lucas Tavares Leme ${ }^{1 *}$, Leandro Augusto dos Reis
}

\begin{abstract}
RESUMO
Com o advento da pandemia da Covid-19 e as condições por ela impostas, as Tecnologias Digitais da Informação e Comunicação (TDIC) passam a ser utilizadas como a ferramenta educacional necessária para a continuação das aulas de música em tempos de distanciamento físico. Tais ações educacionais foram classificadas como Ensino Remoto Emergencial - ERE. Neste cenário, surgem alguns desafios para o ensino de música, uma vez que as ferramentas digitais utilizadas no ERE apresentam alguns problemas como latência, fidelidade sonora e sincronização - aspectos importantes para as práticas musicais. Assim como em uma sinfonia, em três movimentos, este artigo se propõe a discutir o ERE no contexto da educação musical e a importância da tomada de consciência do processo pedagógico por parte do professor. No primeiro movimento, trata-se do conceito de ERE por meio de revisão de literatura. Já no segundo movimento, busca-se na teoria piagetiana a compreensão da construção de significação do sujeito em suas especificidades, no processo de apreensão de si mesmo e do mundo, dos modos de construí-lo e transformálo, em uma relação entre objetivação e subjetivação. E, por fim, no terceiro movimento, apresenta-se uma experiência empírica em andamento. Espera-se que, a partir das reflexões a serem realizadas, ampliem-se as possibilidades para pensar os processos de ensino e aprendizagem de música em diferentes contextos e para além deste contexto de excepcionalidades.
\end{abstract}

Palavras-chave: Ensino Remoto Emergencial de Música; Significações de professores; Pandemia da Covid-19.

\section{ABSTRACT}

With the advent of the Covid-19 pandemic and the conditions imposed by it, Digital Information and Communication Technologies (DICT) are now used as the necessary educational tool for the continuity of music classes in times of physical distance. Such educational actions were classified as Emergency Remote Teaching - ERT. In this scenario, some challenges arise for music teaching, since the digital tools used in the ERT present some problems such as latency, sound fidelity and synchronization - important aspects for musical practices. This article proposes to discuss the ERT in the context of music education and the importance of the teacher's awareness of the pedagogical process, in three movements, as in a symphony. The first movement deals with the concept of ERT through a literature review. In the second movement, Piagetian theory seeks to understand the construction of the subject's meaning in its specificities, in the process of apprehending oneself and the world, in the ways of building and transforming it, in a relationship between objectification and subjectivation. And, finally, in the third movement, an empirical experience in progress is presented. It is expected that, from the reflections to be carried out, the possibilities of thinking about the teaching and learning processes of music in different contexts and beyond this exceptional context will be expanded.

${ }^{1}$ Universidade Estadual de Londrina - UEL.

*E-mail: lucas.tavares.leme@uel.br 
Keywords: Emergency Remote Teaching of Music. Significations of Teachers. Music Education. Covid19 pandemic.

\section{PRELÚDIO}

As condições impostas pela pandemia da Covid-19, dentre elas a necessidade dedistanciamento social, fez com que o uso das Tecnologias Digitais da Informação e Comunicação (TDIC) - que envolve a utilização da internet, do telefone, assim como outros programas e aplicativos que utilizam esses meios - fosse a principal ferramenta educacional necessária para a continuação das aulas. Tais ações educacionais foram classificadas como Ensino Remoto Emergencial - ERE (HODGES et al., 2020). Neste sentido, recentes descobertassobre o ERE têm direcionado a literatura da área a explorar o conceito de ação pedagógica, umdos mais importantes elementos na relação de ensino e aprendizagem, propiciada na interação entre professor e aluno (RONDINI; PEDRO; DUARTE, 2020). Nesta concepção, a ação pedagógica está associada à materialização do fazer educacional, com seus modos de ensinar eaprender (LIMA; PIMENTA, 2006).

Em pesquisas sobre educação, a ação pedagógica pode ser definida como um encontro educativo entre sujeitos e suas circunstâncias, sendo necessária a análise da subjetividade e construção histórica dos sujeitos e das especificidades dessas interações (FRANCO, 2016). Os estudos desenvolvidos por Althaus e Bagio (2017) apontam, ainda, que a ação pedagógica é umvalioso construto pois expressa as dimensões educacionais mais relevantes no processo educativo - concepções, ideologias e estratégias didáticas.

Contudo, em relação às ações pedagógicas no ERE, houve novos desafios educacionaiscomo a manutenção no link de acesso, em manter os alunos concentrados, além da dificuldadede ler as expressões corporais dos alunos, considerando seu ambiente pouco interativo, como aponta Arruda (2020). Especificamente no domínio do ERE de música, em que as aulas virtuaisapresentam problemas de latência, fidelidade sonora e sincronização, há um nível ainda mais desafiador, uma vez que as plataformas digitais não foram pensadas para as atividades e performances musicais (BARROS, 2020).

Assim, existe um interesse crescente em compreender e oferecer subsídios para as açõespedagógico-musicais no ERE (OLIVEIRA; PEREIRA, 2020). Na música, as ações pedagógicason-line encontram uma grande oportunidade de expansão motivada pela geração de nativos digitais, os quais “já nasceram imersos nesta cultura da interação via 
internet $[\ldots]$, e utilizam essa tecnologia como ferramenta para as suas atividades cotidianas, nos processos de aprendizagem e socialização" (ARROYO; BECHARA; PAARMANN, 2017, p. 69).

Em relação às ações pedagógico-musicais, tais argumentos nos direcionam ao conceitode significação, analisado amplamente na literatura pautada na teoria de Jean Piaget (1896- 1980), fundador da Epistemologia Genética, que investiga a evolução biológica-cognitiva da construção do conhecimento (ABREU et al., 2010). Para Reis e Oliveira (2021), compreenderas ações pedagógico-musicais revela-se um importante instrumento para produzir reflexões e possibilidades pedagógicas, contribuindo para o desenvolvimento da Educação Musical nos diferentes contextos de ensino.

\section{PRIMEIRO MOVIMENTO: ENSINO REMOTO EMERGENCIAL DE MÚSICA}

Uma recente definição afirma que o ERE consiste em um modo de ensino alternativo que busca promover interações entre professor e aluno de modo flexível, "que seja rápida de configurar e esteja disponível de forma confiável durante uma emergência ou crise" (HODGES et al., 2020, p. 13, tradução nossa). O conceito por trás dessa definição é o de ensino remoto, eé o gerenciamento desse ensino remoto que permite que os professores desenvolvam interaçõesconstrutivas com seus alunos. De acordo com Freire (1996, p. 47), “ensinar não é transferir conhecimento, mas criar as possibilidades para a sua própria produção ou a sua construção", e o ERE, com sua forma alternativa e pouco interativa, oferece desafios aos professores para o alcance desses objetivos.

No contexto do ERE, a educação brasileira tem enfrentado não apenas entraves relacionados aos conteúdos programáticos ou metodologias de ensino, pois engloba o agravamento da vulnerabilidade socioeconômica dos alunos (BARRETO; ROCHA, 2020). Segundo relatório do Grupo Banco Mundial (2021), a pandemia impactou brutalmente a educação dos alunos mais desfavorecidos economicamente na América Latina, aumentando ematé $65 \%$ a pobreza de aprendizagem, ou seja, quando o aluno é incapaz de ler e compreender um texto simples.

Rondini, Pedro e Duarte (2020) explicam o prejuízo educacional causado pela ausênciadas aulas presenciais. Os autores, a partir da investigação da percepção de 170 professores da Educação Básica, concluem que o ensino presencial possibilita a socialização e a interação entreprofessor-aluno e aluno-aluno, algo ainda desafiador na 
modalidade remota. Neste sentido, a socialização e interação são fatores relevantes para a ação pedagógica, pois é a oportunidade deo professor entrar em contato com seu aluno, que irá direcionar seus esforços pedagógicos (RONDINI; PEDRO; DUARTE, 2020).

Assim, o ERE revela-se um importante construto à literatura sobre Educação. A pesquisa neste tema já reconhece que ambos os momentos - síncronos e assíncronos podem possibilitar aos alunos experiências ativas (MOREIRA; BARROS, 2020; MATOS, 2021). Como apontou Hodges et al. (2020), não podemos voltar às nossas ações pedagógicas antes da pandemia esquecendo o ERE. A literatura em educação póspandemia endossa isso: estamos imersos no mundo globalizado e conectados pelas TDIC, por isso faz-se necessária a inserção dessas tecnologias no cenário educacional (COUTO; COUTO; CRUZ, 2020; BARRETO; ROCHA, 2020). Achados recentes corroboram, ainda, que as TDIC com sua conectividade, fluidez, e apropriação de recursos audiovisuais afeta não só a maneira como o sujeito aprende,mas também como constrói seu saber, como revelam Santos, Alves e Porto (2018).

Means, Bakia e Murphy (2014) propuseram um modelo de avaliação da aprendizagem on-line capaz de indicar os aspectos relevantes para sua implementação e manutenção. Contudo,na condição específica do ERE, Hodges et al. (2020) recomendam a avaliação baseada no modelo CIPP (STUFFLEBEAM; ZHANG, 2017), no qual é estruturado em quatro fatores. CIPP é um acrônimo que representa context ou contexto; input ou entrada; process ou processoe product ou produto. Quais sejam:

1- Contexto: refere-se aos aspectos do contexto institucional, social e governamental, um conjunto de interações que impactam na percepção sobre o ERE.

2- Entrada: concernente ao desenvolvimento profissional e infraestrutura tecnológica paraas necessidades do ERE.

3- Processo: referindo-se às barreiras, desafios e adaptação por parte de professores, alunose equipe escolar.

4- Produto: ofeedback dos envolvidos acerca do ERE permite o destaque dos pontos fortes e a identificação dos pontos que precisam ser revistos no que tange às taxas de conclusãode curso, avaliações, etc.

A literatura recente indica, ainda, a validação do trabalho dos autores em campos educacionais específicos, tais como engenharia (THURAB-NKHOSI; MAHARAJ; 
RAMADHAR, 2021), desenvolvimento de software (TRINTA; REGO; VIANA, 2020) e ensino de inglês (MEDINA, 2021). Esses estudos certificam a estrutura interna do modelo CIPP, de modo a corroborar sua capacidade em avaliar o ERE.

A educação musical no Brasil possui pelo menos duas acepções: uma que diz respeito ao processo de ensino e aprendizagem de música em múltiplos contexto, e outra acepção, por sua vez, reconhece-a como uma área do conhecimento acadêmico-científico (SOUZA, 2020). Sobre isso, Arroyo (2002) admite que o termo Educação Musical envolve uma teia complexa de aspectos teóricos e práticos, podendo ocorrer em contextos, grupos sociais e culturas diversas.

Nos estudos da área da Educação Musical, Reis e Oliveira (2021), em uma recente produção empírica, destacam a visão de licenciandos em música por meio das dimensões das significações de músico e de professor. Há ainda um corpo de conhecimento dedicado à compreensão das ações e concepções de professores de música na educação especial (NICOLODELLI, 2018), na prática coral (DIAS, 2014) e na atividade de estágio refletindo sobre conceitos e saberes da ação pedagógico-musical (AZEVEDO, 2007).

No que tange às ações pedagógico-musicais em tempos de pandemia, Larruscain e Louro (2021, p. 2) admitem que o "dilema em questão é saber quais alternativas os professoresde música encontraram durante esse período para compensar o distanciamento [físico] com osalunos". O resultado da narrativa dos professores nessa pesquisa revela a desigualdade entre osmodelos de educação pública e privada; que a pandemia engendrou a inovação e transformaçãode práticas de ensino, como também, que a cultura digital propicia novas possibilidades de aprendizagem para a população com acesso. A literatura consultada concorda que a ação pedagógico-musical ganhou um novo direcionamento com o ERE, observando a ação pedagógica na especificidade de cada contexto (BARROS, 2020).

\section{SEGUNDO MOVIMENTO: SIGNIFICAÇÃO NA PERSPECTIVA PIAGETIANA}

A perspectiva teórica Piagetiana constitui uma ampla produção científica que se expandiu na última década dado ao notável desenvolvimento de estudos empíricos e teóricos nos diversos contextos educacionais no Brasil (NOVÔA; FRANCO; SILVA, 2018). Desta forma, é basilar que investigações que utilizam a teoria de Piaget considerem a construção de significação do sujeito em suas especificidades, no processo de apreensão 
de si mesmo e do mundo, dos modos de construí-lo e transformá-lo, em uma relação entre objetivação e subjetivação (BECKER, 2001).

Em relação ao processo de construção do conhecimento, os estudos de Piaget descrevemo desenvolvimento dos mecanismos do pensamento, um processo em que diferentes fases do desenvolvimento humano podem ser identificadas. Os resultados indicam que os mecanismos do pensamento constituem e se integram em termos de sete dimensões estruturantes: equilibração; fazer e compreender; tomada de consciência; abstração; generalização; possíveis e circularidade dialética (REIS, 2020). É inegável que a tradição de pesquisa em construção doconhecimento ganhou um novo direcionamento com os estudos de Piaget, ao "descobrir aspectos desconhecidos do funcionamento do pensamento" (DELVAL, 2002, p. 80).

Segundo Becker (2001, p. 74), por meio da apropriação da ação - fazer e compreender, os sujeitos podem desenvolver um processo de construção de conhecimento "extraindo das próprias ações ou operações novas possibilidades para suas dimensões ou capacidades”. Nesseprocesso, Oliveira, Bianchini e Reis (2019) apontam que uma forma de os sujeitos conferirem sentido à realidade é através da significação atribuída a tais ações, tornando a tomada de consciência em elemento central a essa discussão.

Uma vez que a tomada de consciência "é um sistema dinâmico em permanente atividade" (PIAGET, 1977, p. 197), Saravali e Guimarães (2007), argumentam ser plausível usar a mesma heurística que conduz o avanço de um conhecimento menos elaborado para um conhecimento mais elaborado envolvendo a tomada de consciência. Para Piaget (1978, p. 126)a tomada de consciência "é uma reconstituição conceitual do que tem feito a ação", no qual o uso simbólico da linguagem é explicado pelo fato de que, como seres humanos, somos "capazes de compreender nossa própria capacidade de conhecer" (BECKER, 2001, p. 78).

Diante disso, Silva e Frezza (2011, p. 193) afirmam que a significação está associada aoprocedimento encontrado pelo indivíduo frente aos problemas, ou seja, "a organização dos comportamentos em suas características processuais”. Neste sentido, a significação de uma situação é construída a partir das inúmeras trocas que o indivíduo realiza ativamente com o meio, especialmente aquelas efetivadas em confronto com o novo, estabelecidas num contexto de estranhamento e desequilíbrio (BIANCHINI; VASCONCELOS, 2014). Ademais, a construção da significação depende do grau de 
novidade que eles representam para o indivíduo e a complexidade da problemática envolvida (SILVA; FREZZA, 2011).

Nessa perspectiva, Reis e Oliveira (2021) conduziram uma investigação sobre as significações dos licenciandos em música acerca dos papéis de músico e professor, identificando cinco dimensões das suas significações: saber fazer; compreender; ensino; técnica/intelectual e esquemas de ação. Para os autores, a análise das significações dos professores de música permite compreender os mecanismos do pensamento, tornando-se uma importante ferramenta para o desenvolvimento pedagógico-musical.

Não obstante, a literatura em Educação Musical reclama o desenvolvimento de pesquisas empíricas sobre os mecanismos do pensamento de Piaget na Educação Musical (REIS; OLIVEIRA, 2021). Em similitude, Novôa, Franco e Silva (2018) admitem que a teoriade Piaget configura uma crescente arena de pesquisa. Os autores justificam, então, a necessidade de desenvolvimento de trabalhos nesse tópico, já que eles podem contribuir com oconhecimento sobre o desenvolvimento humano e aprendizagem. Os autores apontam, ainda, que tais pesquisas são um primeiro passo para a difusão da teoria de Piaget na área da educação,considerando a complexidade dos fenômenos da aprendizagem e os diferentes contextos educacionais no Brasil.

\section{TERCEIRO MOVIMENTO: EXPERIÊNCIA EMPÍRICA}

O principal objetivo desta pesquisa em andamento é analisar as significações dos professores de música acerca do ERE à luz da perspectiva piagetiana. Para cumprir este propósito, será realizada uma pesquisa qualitativa que visa identificar os mecanismos do pensamento evidenciadosnas significações de três professores de música do município de Londrina, Paraná. Para a coleta de dados, serão realizadas entrevistas com cada um dos participantes. Como instrumento de coleta de dados, será desenvolvido um roteiro de entrevista semiestruturada. Em relação a análise de dados, recorrer-se-á ao método clínico-crítico como princípio metodológico.

Este trabalho reportará os resultados de uma pesquisa de cunho qualitativo, uma vez que $\mathrm{l}$ abordagem visa a compreensão dos fenômenos sociais levando em conta sua natureza experiencial e subjetiva dos dados (BOGDAN; BIKLEN, 1994). Tal proposta está vinculada ao projeto de pesquisa intitulado "Mecanismos cognitivos e ato criativo: significações atribuídas à música-jogo em contexto de oficinas", cadastrado na 
PROPPG (n. 12492) e aprovado pelo Comitê de Ética em Pesquisa Envolvendo Seres Humanos da Universidade Estadual de Londrina (PARECER N. 4.096.667).

Diante do exposto, o presente estudo problematiza: quais são as significações dos professores de música acerca do ERE? Esta investigação visa analisar as significações dos professores de música acerca do ERE. Elencou-se quatro objetivos específicos, a saber:

- Compreender os aspectos do contexto institucional dos participantes, um conjunto deinterações que impactaram na percepção sobre o ERE;

- Apontar o desenvolvimento profissional e infraestrutura tecnológica dos participantes paraas necessidades do ERE;

- Identificar as dificuldades, desafios e possibilidades encontradas pelos participantes noERE;

- $\quad$ Refletir sobre o feedback dos participantes, o destaque dos pontos fortes e a identificação dos pontos que precisam ser revistos para futuras ações pedagógicomusicais em ambientevirtual.

Como auxílio à condução das entrevistas semiestruturadas, será desenvolvido um roteiro, cuja intenção é nortear a interação entre pesquisador e entrevistado (DELVAL, 2002). Os sujeitos da pesquisa serão quatro professores de música do município de Londrina, Paraná. Haja vista que os professores de música configuram um grupo restrito dentro dapopulação de docentes (BRASIL, 2019), optou-se em enviar convites diretamente aosprofessores em suas redes sociais. Assim, será desenvolvido uma carta convite encaminhada aos professores de música que atuam ou atuaram durante a pandemia. As entrevistas ocorrerão por meio da plataforma digital google Meet. Todos os participantes assinarão um Termo de Consentimento Livre e Esclarecido - TCLE.

Em relação a análise de dados, recorrer-se-á ao método clínico-crítico como princípio metodológico, uma vez que permite analisar aspectos processuais do pensamento do adulto (SILVA; FREZZA, 2011). Segundo Delval (2002, p. 12), o método clínico-crítico auxilia o pesquisador a compreender "como o sujeito representa a situação e organiza sua ação", o que converge com o intuito deste trabalho. Os dados coletados serão estruturados com base no modelo de avaliação CIPP de Stufflebeam e Zhang (2017; HODGES et al., 2020), dando origema categorias, que resultarão na análise dos dados.

\section{CODA: CONSIDERAÇÕES FINAIS}


Espera-se que este estudo possa provocar a reflexão acerca da temática e amplie as possibilidades para pensar os processos de ensino e aprendizagem de música em diferentes contextos, como no caso do Ensino Remoto Emergencial de música. Deste modo, que os professores de música possam se apropriar de tais conhecimentos como um dos pontos de partida para a reflexão e reestruturaçãode suas ações pedagógicomusicais para além das condições impostas pelo contexto emergencial da pandemia.

\section{REFERÊNCIAS}

ALTHAUS, Maiza Taques Margraf; BAGIO, Viviane Aparecida. As metodologias ativas eas aproximações entre o ensino e a aprendizagem na prática pedagógica universitária. Revista Docência Do Ensino Superior, v. 7, n. 2, p. 79-96, 2017.

ARROYO, Margarete. Educação musical na contemporaneidade. In: SEMINÁRIO NACIONAL DE PESQUISA EM MÚSICA DA UFG, 2, 2002, Goiânia. Anais [...]. Goiânia:UFG, 2002 p. 18-29.

ARROYO, Margarete; BECHARA, Silvia Regina CC; PAARMANN, Herald. Educaçãomusical, juventude e pesquisa na internet: compartilhando procedimentos metodológicos. Opus, v. 23, n. 3, p. 67-90, 2017.

ARRUDA, Eucidio Pimenta. Educação remota emergencial: elementos para políticas públicas na educação brasileira em tempos de Covid-19. Em Rede-Revista de Educação a Distância, v. 7, n. 1, p. 257-275, 2020.

AZEVEDO, Maria Cristina de Carvalho Cascelli de. Os saberes docentes na ação pedagógica dos estagiários de música: dois estudos de caso. 2007. Tese (Doutorado em Educação Musical) - Instituto de Artes, Universidade Federal do Rio Grande do Sul, PortoAlegre, 2007.

BARRETO, Andreia Cristina Freitas; ROCHA, Daniele Santos. Covid 19 e educação: resistências, desafios e (im) possibilidades. Revista Encantar-Educação, Cultura e Sociedade, v. 2, p. 01-11, 2020.

BARROS, Matheus Henrique da Fonseca. Educação musical, tecnologias epandemia. OuvirOUver, v. 16, n. 1, p. 292-304, 2020.

BECKER, Fernando. Educação e construção do conhecimento. Porto Alegre:Artmed, 2001.

BIANCHINI, Luciane Guimarães Batistella; VASCONCELOS, Mario Sergio.

Significação esentimentos dos alunos quando erram na matemática. Programa de Estudos Pós- Graduados em Educação: Psicologia da Educação. n. 38, p. 63-71, 2014. 
BOGDAN, Robert; BIKLEN, Sari. Investigação qualitativa em educação: uma introduçãoà teoria e aos métodos. Porto, Portugal: Porto Editora, 1994.

BRASIL. Censo da Educação Superior 2019. Ministério da Educação. Instituto Nacionalde Estudos e Pesquisas Educacionais Anísio Teixeira, 2019. disponível em: https://www.gov.br/inep/pt-br/areas-de-atuacao/pesquisas-estatisticas-eindicadores/censo- da-educacao-superior/resultados. Acesso em: 11 out. 2021

COUTO, Edvaldo Souza; COUTO, Edilece Souza; CRUZ, Ingrid de Magalhães Porto. \#fiqueemcasa: educação na pandemia da COVID-19. Interfaces Científicas-Educação, v. 8,n. 3, p. 200-217, 2020.

DELVAL, Juan. Introdução à prática do método clínico: descobrindo o pensamento dascrianças. Artmed, 2002.

DIAS, Leila Miralva Martins. Interações pedagógico-musicais da prática coral. Revista daABEM, v. 20, n. 27, P. 131-140, 2014.

FRANCO, Maria Amélia do Rosario Santoro. Prática pedagógica e docência: um olhar a partir da epistemologia do conceito. Revista Brasileira de Estudos Pedagógicos, v. 97, p.534-551, 2016.

FREIRE, Paulo. Pedagogia da autonomia. São Paulo: Editora Paz e Terra, 1996.

HODGES, Charles et al. The difference between emergency remote teaching and online learning. Educause review, v. 27, p. 1-12, 2020.

GRUPO BANCO MUNDIAL. Agir agora para proteger o capital humano de nossas crianças: Os custos e a Resposta ao Impacto da pandemia da COVID- no Setor de Educaçãona América Latina e no Caribe. 2021. Disponível em: https://openknowledge.worldbank.org/bitstream/handle/10986/35276/Acting\%20nowsumPT.pdf?sequence=13\&isAllowed=y. Acesso em: 03 set. 2021 .

LARRUSCAIN, Edilacir dos Santos; LOURO, Ana Lúcia. Experiências de professores de música na pandemia: narrativas sobre espaços públicos e privados. Revista da FUNDARTE,v. 44, n. 44, p. 1-15, 2021.

LIMA, Maria Socorro Lucena; PIMENTA, Selma Garrido. Estágio e docência: diferentesconcepções. Poieis pedagógica, v. 3, n. 3 e 4, p. 5-24, 2006.

MATOS, Ronaldo. Possibilidades de ensino remoto de música na educação básica baseadasno material Música Br. Música na Educação Básica, v. 10, n. 12, p. 74-95, 2021.

MEANS, Barbara; BAKIA, Marianne; MURPHY, Robert. Learning online: What researchtells us about whether, when and how. Routledge, 2014. 
MEDINA, Sergio Alonso Lopera. An Online English Teaching Experience during Covid-19Pandemic: Preliminary Findings. Linguiística y Literatura, v. 42, n. 80, p. 203-220, 2021.

MOREIRA, Darlinda; BARROS, Daniela Melaré Vieira. Orientações práticas para a comunicação síncrona e assíncrona em contextos educativos digitais. EduCAPES, 2020.E-book. Disponível em: Moreira \& Barros (2020) Sincrono\&assíncrono_revisto (uab.pt). Acesso em: 05 out. 2021.

NICOLODELLI, Vinicius. O educador musical na educação especial: a trajetória de três professores. Revista NUPEART, v. 19, n. 19, p. 120-139, 2018.

NOVÔA, Nicássia Feliciana; FRANCO, Simone Carla Delfino; SILVA, Helder Antônio. Teoria de Piaget: revisão sistemática da produção acadêmica no campo da educação. Argumentos Pró-Educação, v. 3, n. 7, p. 118-134, 2018.

OLIVEIRA, Francismara Neves de; BIANCHINI, Luciane Guimarães Batistella; REIS, Leandro Augusto dos. Significações do professor e indicadores de resiliência em estudantescom dificuldades de aprendizagem em matemática. ETD-Educação

Temática Digital, v. 21, n. 2, p. 416-434, 2019.

OLIVEIRA, Mário André Wanderley de; PEREIRA, Marcus Vinicius Medeiros. (Re) Açõesda Associação Brasileira de Educação Musical em tempos de pandemia: entre adaptações e aconstrução de um novo futuro. Revista Música, v. 20, n. 2, p. 239-258, 2020.

PIAGET, Jean. A Tomada de Consciência. São Paulo: Melhoramentos, 1977.

PIAGET, Jean. Epistemologia Genética; Sabedoria e Ilusões da filosofia e Problemas de Psicologia Genética. In: Os pensadores. São Paulo: Abril Cultural, 1978.

REIS, Leandro Augusto dos. Músico na sala de aula ou professor no palco? Significaçõesde licenciandos em Música - encontros possíveis. 2020. 169f. Tese (Doutorado em Educação) - Universidade Estadual de Londrina, Londrina, 2020.

REIS, Leandro Augusto dos; OLIVEIRA, Francismara Neves de. Dimensões das significações de músico e de professor: um estudo com licenciandos em música. RevistaIbero-Americana de Estudos em Educação, p. 735-748, 2021.

RONDINI, Carina Alexandra; PEDRO, Ketilin Mayra; DUARTE, Cláudia dos Santos. Pandemia do Covid-19 e o ensino remoto emergencial: Mudanças na práticadocente. Interfaces Científicas-Educação, v. 10, n. 1, p. 41-57, 2020.

SANTOS, Fábio Maurício Fonseca; ALVES, André Luiz; PORTO, Cristiane de Magalhães.Educação e tecnologias. Revista Científica da FASETE, v. 44, p. 1-18, 2018.

SARAVALI, Eliane Giachetto; GUMARÃES, Karina Perez. Dificuldades de aprendizagem e conhecimento: um olhar à luz da teoria piagetiana. Olhar de Professor, Pomta Grossa, v. 10, n. 2, p. 117-139, jul./dez. 2007. 
SILVA, João Alberto da; FREZZA, Júnior Saccon. Aspectos metodológicos e constitutivosdo pensamento do adulto. Educar em revista, n. 39, p. 191-205, 2011.

SOUZA, Jusamara. A Educação Musical como campo científico. Olhares \& Trilhas, v. 22,n. 1, p. 9-24, 2020.

STUFFLEBEAM, Daniel L.; ZHANG, Guili. The CIPP evaluation model: How to evaluate for improvement and accountability. Guilford Publications, 2017.

THURAB-NKHOSI, Dianne; MAHARAJ, Chris; RAMADHAR, Varun. The impact of emergency remote teaching on a blended engineering course: perspectives and implicationsfor the future. SN Social Sciences, v. 1, n. 7, p. 1-19, 2021.

TRINTA, Fernando; REGO, Paulo AL; VIANA, Windson. Teaching Development of Distributed Software during COVID-19: An experience report in Brazil. In:

Proceedings ofthe 34th Brazilian Symposium on Software Engineering. 2020. p. 616-625.

\section{Recebido em: 05/01/2022}

Aprovado em: 08/02/2022 